\title{
Oxidative Stress Status Increase in Patients with Nonischemic Heart Failure
}

\author{
Mustafa Karabacak $^{a}$ Abdullah Dogan ${ }^{b}$ Senol Tayyar ${ }^{c}$ Hasan Aydın Bas ${ }^{a}$ \\ ${ }^{a}$ Department of Cardiology, Isparta State Hospital, and b Department of Cardiology, Suleyman Demirel University, \\ Isparta, and ' Umit Visnelik Private Hospital, Eskisehir, Turkey
}

\section{Key Words}

Heart failure - Oxidative stress index · Total oxidative stress . Uric acid

\begin{abstract}
Objective: It was the aim of this study to investigate the serum oxidative stress level in nonischemic patients with heart failure (HF). Subjects and Methods: The study included 37 patients who presented to the Department of Cardiology, Suleyman Demirel University, Isparta, Turkey, with a diagnosis of asymptomatic HF (New York Heart Association class III). The patients had a left ventricular (LV) ejection fraction (EF) of $\leq 40 \%$ and normal coronary arteries or nonsignificant stenosis (stenosis $<40 \%$ ). In addition, 30 age- and sexmatched normal patients were selected as the control group. Clinical and laboratory characteristics presumed to be associated with oxidative stress were evaluated. Results: Demographic characteristics were comparable. However, creatinine and potassium levels were higher in the $\mathrm{HF}$ than in the control group. Total oxidative status $\left[2.42 \mu \mathrm{mol} \mathrm{H}_{2} \mathrm{O}_{2} \mathrm{Eq} / \mathrm{l}\right.$ (range $0.74-5.86$ ) vs. $1.81 \mu \mathrm{mol} \mathrm{H}_{2} \mathrm{O}_{2} \mathrm{Eq} / \mathrm{l}$ (range $0.42-3.45$ ); $\mathrm{p}<0.01$ ], oxidative stress index [2.24 (range $0.63-5.33$ ) vs. 1.53 (range $0.28-2.51) ; \mathrm{p}<0.01$ ] and uric acid $(6.1 \pm 1.8 \mathrm{vs.} 4.4$ $\pm 1.1 \mathrm{mg} / \mathrm{dl} ; \mathrm{p}<0.01$ ) levels were significantly higher in the
\end{abstract}

HF than in the control group. The total antioxidant capacity was similar in both groups $[1.22 \mathrm{mmol}$ Trolox Eq/l (range $0.61-1.99$ ) vs. $1.18 \mathrm{mmol}$ Trolox Eq/l (range $0.82-1.80$ ); $\mathrm{p}=$ 0.77]. The $\gamma$-glutamyltransferase levels were also comparable in both groups [32 U/I (range 11-106) vs. $23 \mathrm{U} / \mathrm{l}$ (range 1172); $p=0.10]$. Conclusion: The oxidative stress levels were higher in HF patients, and hence, oxidative stress may play an important role in poor prognosis of HF. Therefore, antioxidant treatment might be reasonable.

(C) 2014 S. Karger AG, Basel

\section{Introduction}

Heart failure (HF) has a poor prognosis despite new improvements in its management [1]. Activation of the sympathetic nervous system is one of the major pathophysiological abnormalities in HF patients $[1,2]$. It leads to ventricular remodeling and progression of cardiac dysfunction through various mechanisms, including oxidative stress [2]. Moreover, HF is a state of chronic deterioration of oxidative mechanisms due to enhanced oxidative stress and consequent subcellular alterations [3].

Oxidative stress is defined as an excess production of reactive oxygen species (ROS) relative to the levels of an-

\begin{tabular}{ll}
\hline KARGER & $\begin{array}{l}\text { ( ) 2014 S. Karger AG, Basel } \\
1011-7571 / 14 / 0236-0532 \$ 39.50 / 0 \quad \text { Karger }\end{array}$ \\
$\begin{array}{l}\text { E-Mail karger@karger.com } \\
\text { www.karger.com/mpp }\end{array}$ & $\begin{array}{l}\text { Thisis an Open Access article licensed under the terms of the } \\
\text { Creative Commons Attribution-NonCommercial 3.0 Un- } \\
\text { ported license (CC BY-NC) (www.karger.com/OA-license), } \\
\text { applicable to the online version of the article only. Distribu- } \\
\text { tion permitted for non-commercial purposes only. }\end{array}$
\end{tabular}

Mustafa Karabacak, MD

Modern Evler Mah 142. Cadde

İksir Sitesi No. 7/10

TR-32100 Isparta (Turkey)

E-Maildrmustafa1979@hotmail.com 
tioxidants, thereby creating an imbalance between proand antioxidant factors in favor of pro-oxidants, and so potentiating oxidative damage [4]. Over several decades, clinical and experimental studies have provided substantial evidence that increased oxidative stress could lead to HF [5-8].

It is difficult to measure each antioxidant separately because of the number of different antioxidants in plasma, serum, urine or other biological samples. Thus, measurements of the total antioxidant capacity (TAC) and total oxidant status (TOS) have been used in assessing oxidant and antioxidant systems in organisms $[9,10]$. In addition, the oxidative stress index (OSI), the ratio of the total plasma TOS level to TAC, is an indicator of oxidative stress, reflecting the redox balance between oxidation and antioxidation $[9,11]$. Therefore, studying the overall antioxidant status may be more biologically relevant than evaluating a single antioxidant.

Increased generation of ROS has been described in patients with congestive HF; ROS may play an important role in the sudden death of these patients [5, 12-14]. To the best of our knowledge, there is only one study on plasma TOS, TAC levels and OSI, a method for global oxidative stress, in patients with dilated cardiomyopathy in the literature [15], and we have found that the oxidative status in patients with nonischemic HF was not evaluated. Hence, we aimed to evaluate the global oxidative status in patients with nonischemic HF.

\section{Subjects and Methods}

\section{Patients and Study Drugs}

Seventy-one consecutive patients presented to the Department of Cardiology with a diagnosis of asymptomatic HF (New York Heart Association class I-II) between June 2011 and August 2013. They had undergone coronary angiography to define the etiology of HF, with normal coronary arteries or nonsignificant stenosis (stenosis $<40 \%$ ) and a left ventricular (LV) ejection fraction (EF) of $\leq 40 \%$ in the previous 3 months. Forty-four patients were excluded from the study (detailed below). The remaining 37 patients were included in the patient group. In addition, 30 age- and sexmatched normal patients recruited from the population were included as the control group.

Exclusion criteria were HF with significant coronary stenosis, history of myocardial infarction, moderate or severe valvular heart disease, severe hypertension (systolic blood pressure $\geq 180 \mathrm{~mm} \mathrm{Hg}$ and/or diastolic blood pressure $\geq 120 \mathrm{~mm} \mathrm{Hg}$ ), peripheral arterial disease, diabetes mellitus, dyslipidemia (either a low-density lipoprotein cholesterol level of $\geq 155 \mathrm{mg} / \mathrm{dl}$, a triglyceride level of $\geq 200$ $\mathrm{mg} / \mathrm{dl}$ or the use of lipid-lowering drugs), hypo- or hyperthyroidism, hepatic or renal failure (serum creatinine $>2.0 \mathrm{mg} / \mathrm{dl}$ ), hematological disorders, history of malignancy, inflammatory or infectious disease, asthma, chronic obstructive pulmonary disease, ob- structive sleep apnea syndrome, Cheyne-Stokes respiration, cigarette smoking, alcohol use, and any drug use that may affect the oxidative stress status. All study and control patients gave informed consent, and the study was approved by the institution's Ethics Committee.

Complete blood counts, biochemical analyses and echocardiographic measurements were made of all study subjects. Heart rate, blood pressure and body weight were measured. All medications were administered according to the current chronic HF guidelines [1]. All patients received $\beta$-blockers, angiotensin-converting enzyme inhibitors (lisinopril) and diuretics (spironolactone, thiazides, furosemide) in appropriate doses. Angiotensin receptor blockers were given when intolerance to angiotensin-converting enzyme inhibitor occurred.

\section{Blood Sample Collection}

Blood samples were drawn from an antecubital vein by careful venipuncture using a 21 -gauge needle without stasis between 08.00 and $10.00 \mathrm{a}$.m. after a resting time of $30 \mathrm{~min}$ and a fasting period of $12 \mathrm{~h}$. Routine biochemical parameters were determined by standard methods. Hematological indices were measured within 30 min of collecting the blood samples in tubes containing dipotassium EDTA. Biochemical analyses were performed using an autoanalyzer Olympus AU-640 (Olympus Diagnostica, Hamburg, Germany). An automatic blood counter (Beckman-Coulter Company, Miami, Fla., USA) was used for whole blood counts.

For TAC/TOS measurements, a 5-ml blood sample was collected into a plastic tube containing potassium EDTA. TAC and TOS were measured in every patient and the control group. Blood samples $(4 \mathrm{ml})$ were obtained following overnight fasting. The serum was separated from the cells by centrifugation for $10 \mathrm{~min}$ and then stored at $-80^{\circ} \mathrm{C}$ until biochemical examination. TAC and TOS levels were measured using commercially available kits (Rel Assay, Gaziantep, Turkey). The level of TAC was measured using an automated method [16], based on the bleaching of the characteristic color of a more stable 2,2'-azino-bis(3-ethylbenzothiazoline-6-sulfonic acid) radical cation by antioxidants. The results were expressed in mmol Trolox Eq/l. The level of TOS was measured by a method, in which oxidants present in the sample oxidize the ferrous ion-o-dianisidine complex to ferric ion. The oxidation reaction is enhanced by glycerol molecules abundantly present in the reaction medium. The ferric ion produces a colored complex with xylenol orange in an acidic medium. The color intensity, which was measured spectrophotometrically, was related to the total amount of oxidant molecules present in the sample. The assay was calibrated with hydrogen peroxide and the results were expressed in $\mu \mathrm{mol} \mathrm{H}_{2} \mathrm{O}_{2} \mathrm{Eq} / \mathrm{l}$ [16].

\section{Determination of OSI}

The ratio of TOS to TAC was accepted as the OSI. For calculation, the resulting unit of TAC was converted to $\mathrm{mmol} / \mathrm{l}$, and the OSI value was calculated according to the following formula: OSI $(\mathrm{AU})=\operatorname{TOS}\left(\mu \mathrm{mol} \mathrm{H}_{2} \mathrm{O}_{2} \mathrm{Eq} / \mathrm{l}\right) / \mathrm{TAC}$ (mmol Trolox Eq/l) [11]

\section{Echocardiographic Evaluation}

Echocardiographic examinations were performed by the same investigators M.K. and S.T. who were blinded to the data of patients and controls. Measurements were acquired at the end of expiration during normal breathing in the left lateral decubitus position. Two-dimensional, M-mode echocardiography was obtained 
Table 1. Demographic, clinical and echocardiographic characteristics of the $\mathrm{HF}$ and the control group

\begin{tabular}{|c|c|c|c|}
\hline & $\begin{array}{l}\text { HF group } \\
(\mathrm{n}=37)\end{array}$ & $\begin{array}{l}\text { Control } \\
\text { group } \\
(\mathrm{n}=30)\end{array}$ & $\mathrm{p}$ \\
\hline Mean age, years & $55 \pm 10$ & $58 \pm 12$ & 0.25 \\
\hline Male/female & $23 / 14$ & $15 / 15$ & 0.33 \\
\hline BMI & $27.3 \pm 5.6$ & $25.8 \pm 3.1$ & 0.09 \\
\hline Waist circumference, $\mathrm{cm}$ & $92 \pm 13$ & $91 \pm 10$ & 0.60 \\
\hline Systolic BP, mm Hg & $125 \pm 13$ & $116 \pm 28$ & 0.08 \\
\hline Diastolic BP, mm Hg & $82 \pm 13$ & $78 \pm 13$ & 0.27 \\
\hline Heart rate, bpm & $72 \pm 10$ & $74 \pm 9$ & 0.32 \\
\hline $\mathrm{EF}$ & $30.2 \pm 4.5$ & $64.2 \pm 4.2$ & $<0.01$ \\
\hline LVEDV, $\mathrm{cm}^{3}$ & $214 \pm 31$ & $102 \pm 12$ & $<0.01$ \\
\hline LVESV, $\mathrm{cm}^{3}$ & $149 \pm 28$ & $38 \pm 6$ & $<0.01$ \\
\hline Interventricular septum, $\mathrm{mm}$ & $12.2 \pm 1.0$ & $11.5 \pm 0.9$ & 0.02 \\
\hline Posterior wall, mm & $11.4 \pm 0.7$ & $10.7 \pm 1.1$ & 0.01 \\
\hline Left atrium, mm & $43 \pm 10$ & $37 \pm 4$ & 0.02 \\
\hline
\end{tabular}

$\mathrm{BMI}=$ Body mass index; $\mathrm{BP}=$ blood pressure LVEDV $=\mathrm{LV}$ end-diastolic volume. $\mathrm{p}$ values indicate the comparison between the control and the study population. Figures in bold are significant $(\mathrm{p}<0.05)$.

according to the recommendations of the American Society of Table 2. Laboratory characteristics of the HF and the control group

\begin{tabular}{lccr}
\hline & $\begin{array}{l}\text { HF group } \\
(\mathrm{n}=37)\end{array}$ & $\begin{array}{l}\text { Control } \\
\text { group } \\
(\mathrm{n}=30)\end{array}$ & $\mathrm{p}$ \\
\hline Glucose, $\mathrm{mg} / \mathrm{dl}$ & $102 \pm 18$ & $90 \pm 28$ & 0.05 \\
Creatinine, mg/dl & $1.06 \pm 0.29$ & $0.89 \pm 0.19$ & $<\mathbf{0 . 0 1}$ \\
Sodium, mg/l & $138 \pm 3$ & $138 \pm 5$ & 0.92 \\
Potassium, mg/l & $4.7 \pm 0.5$ & $4.2 \pm 0.5$ & $<\mathbf{0 . 0 1}$ \\
AST, U/l & $22 \pm 7$ & $19 \pm 5$ & 0.13 \\
ALT, U/l & $22 \pm 14$ & $18 \pm 5$ & 0.23 \\
TSH & $1.71 \pm 1.23$ & $1.58 \pm 1.12$ & 0.69 \\
Hemoglobin, g/dl & $13.1 \pm 2.1$ & $14.2 \pm 1.8$ & $\mathbf{0 . 0 2}$ \\
Platelets, $\times 10^{3} / \mathrm{mm}^{3}$ & $237 \pm 57$ & $260 \pm 65$ & 0.12 \\
WBC, $\times 10^{3} / \mathrm{ml}$ & $7.0 \pm 2.0$ & $6.6 \pm 1.6$ & 0.36 \\
RDW, $\%$ & $15.5 \pm 1.5$ & $14.5 \pm 1.5$ & $<\mathbf{0 . 0 1}$ \\
Neutrophils, $\times 10^{3} / \mathrm{ml}$ & $4.46 \pm 1.72$ & $3.73 \pm 1.26$ & 0.08 \\
Lymphocytes, $\times 10^{3} / \mathrm{ml}$ & $1.78 \pm 0.85$ & $2.20 \pm 0.61$ & 0.05 \\
NLR & $3.01 \pm 1.69$ & $1.75 \pm 0.53$ & $<\mathbf{0 . 0 1}$ \\
& & &
\end{tabular}

AST = Aspartate transaminase; ALT = alanine transaminase; $\mathrm{TSH}=$ thyroid-stimulating hormone; $\mathrm{WBC}=$ white blood cells; $\mathrm{NLR}$ = neutrophil-lymphocyte ratio. $\mathrm{p}$ values indicate the comparison between the control and the study population. Figures in bold are significant $(\mathrm{p}<0.05)$.
Echocardiography with the System 5 Echocardiography Device (GE Vingmed Ultrasound) with a 2.5- $\mathrm{MHz}$ FPA transducer [17]. Echocardiographic results were calculated as the mean of 3 cardiac cycles during electrocardiographic monitoring. Left atrial size, LV diameters and wall thickness were measured using M-mode echocardiography. LVEF was calculated by Simpson's rule [18].

\section{Statistical Analysis}

Data were analyzed with the SPSS software version 20.0 for Windows. Continuous variables from the study groups were reported as means \pm standard deviations and categorical variables as percentages. To compare continuous variables, the Student t test or Mann-Whitney U test was used, as appropriate. Categorical variables were compared using the $\chi^{2}$ test. Pearson's correlation coefficients were calculated to evaluate the relationships between variables. A 2 -tailed $\mathrm{p}<0.05$ was considered significant.

\section{Results}

Demographic, clinical and echocardiographic characteristics of the patients are given in table 1 . The demographic and clinical characteristics are comparable between the HF patients and the control group. EF [30.2 \pm 4.5 (patients group) vs. $64.2 \pm 4.2$ (control group); $\mathrm{p}<$ 0.01 ], LV end-diastolic volume, LV end-systolic volume (LVESV) and left atrium diameter were higher in the HF group (table 1). Creatinine $[1.06 \pm 0.29 \mathrm{mg} / \mathrm{dl}$ (patient group) vs. $0.89 \pm 0.19 \mathrm{mg} / \mathrm{dl}$ (control group); $\mathrm{p}<0.01$ ], potassium $(4.7 \pm 0.5$ vs. $4.7 \pm 0.5 \mathrm{mg} / \mathrm{dl} ; \mathrm{p}<0.01)$, red blood cell distribution width (RDW; $15.5 \pm 1.5$ vs. $14.5 \pm$ $1.5 \% ; \mathrm{p}<0.01)$ and neutrophil-lymphocyte ratio (3.01 \pm 1.69 vs. $1.75 \pm 0.53 ; \mathrm{p}<0.01$ ) were significantly higher in the HF than in the control group. However, the hemoglobin level was higher in the control compared to the patient group $(13.1 \pm 2.1$ vs. $14.2 \pm 1.8 \mathrm{~g} / \mathrm{dl}$, respectively; $\mathrm{p}=0.02)$. Other laboratory values were similar in the two groups (table 2).

Oxidative stress parameters in the patients with nonischemic HF and the control group are shown in table 3. TOS levels were significantly higher in the patient compared to the control group [2.46 $\mu \mathrm{mol} \mathrm{H}_{2} \mathrm{O}_{2} \mathrm{Eq} / \mathrm{l}$ (range $0.74-5.86$ ) vs. $1.81 \mu \mathrm{mol} \mathrm{H}_{2} \mathrm{O}_{2}$ Eq/l (range 0.42-3.45), respectively; $\mathrm{p}<0.01]$. TAC levels were comparable in both groups [1.20 mmol Trolox Eq/l (range 0.61-1.99) vs. 1.7 mmol Trolox Eq/l (range 0.82-1.80), respectively; $\mathrm{p}=$ 0.77]. The OSI ratio was significantly higher in the patient than in the control group [2.24 (range $0.63-5.33$ ) vs. 1.53 (range 0.28-2.51), respectively; $\mathrm{p}<0.01$; fig. 1]. $\gamma$-Glutamyltransferase [32 U/l (range 11-106) vs. $23 \mathrm{U} / \mathrm{l}$ (range 11-72); $\mathrm{p}=0.10]$ and alkaline phosphatase $(77 \pm$ 36 vs. $70 \pm 18 \mathrm{U} / \mathrm{l} ; \mathrm{p}=0.58$ ) levels were similar in both 


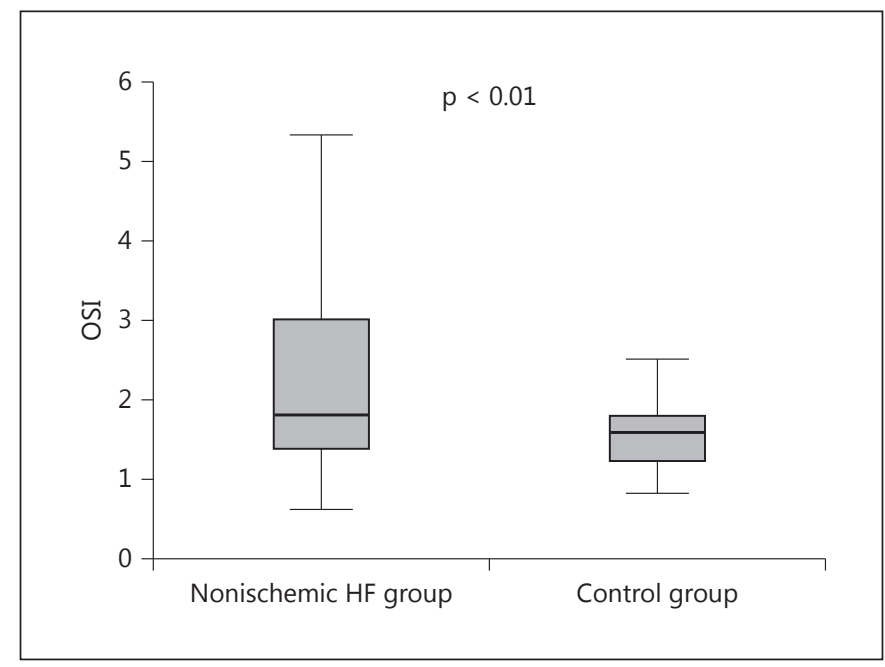

Fig. 1. Change in OSI values in the HF and the control group. The OSI ratio was higher in HF patients compared to control patients [2.18 (range $0.63-3.82$ ) vs. 1.53 (range $0.28-2.51$ ); $\mathrm{p}=0.01$ ].

Table 3. Comparison of parameters associated with oxidative stress in the HF and the control group

\begin{tabular}{lllr}
\hline & $\begin{array}{l}\text { HF group } \\
(\mathrm{n}=37)\end{array}$ & $\begin{array}{l}\text { Control group } \\
(\mathrm{n}=30)\end{array}$ & $\mathrm{p}$ \\
\hline TOS, $\mu \mathrm{mol} \mathrm{H}_{2} \mathrm{O}_{2} \mathrm{Eq} / \mathrm{l}$ & $2.42(0.74-5.86)$ & $1.81(0.42-3.45)$ & $<\mathbf{0 . 0 1}$ \\
TAC, mmol Trolox Eq/l & $1.22(0.61-1.99)$ & $1.17(0.82-1.80)$ & 0.77 \\
OSI, AU & $2.24(0.63-5.33)$ & $1.53(0.28-2.51)$ & $<\mathbf{0 . 0 1}$ \\
ALP, U/l & $77 \pm 36$ & $70 \pm 18$ & 0.58 \\
GGT, U/l & $32(11-106)$ & $23(11-72)$ & 0.10 \\
Uric acid, mg/dl & $6.1 \pm 1.8$ & $4.4 \pm 1.1$ & $<\mathbf{0 . 0 1}$ \\
Hs CRP, mg/l & $7.6 \pm 6.2$ & $4.1 \pm 2.2$ & $<\mathbf{0 . 0 1}$ \\
\hline
\end{tabular}

ALP = Alkaline phosphatase; GGT $=\gamma$-glutamyltransferase; Hs CRP = high-sensitivity C-reactive protein. $\mathrm{p}$ values indicate the comparison between the control and the study population. Figures in bold are significant $(\mathrm{p}<0.05)$.

groups. However, uric acid $(6.1 \pm 1.8$ vs. $4.4 \pm 1.1 \mathrm{mg} / \mathrm{dl}$; $\mathrm{p}<0.01)$ and high-sensitive C-reactive protein $(7.6 \pm 6.2$ vs. $4.1 \pm 2.2 \mathrm{mg} / \mathrm{l} ; \mathrm{p}<0.01$ ) levels were higher in the HF group compared to the control group (table 3 ).

In the correlation analysis, EF $(\mathrm{p}=0.001, \mathrm{r}=-0.43)$ and the TAC level $(\mathrm{p}<0.001, \mathrm{r}=-0.47)$ were negatively correlated with OSI. TOS ( $\mathrm{p}<0.001, \mathrm{r}=0.84)$, uric acid $(\mathrm{p}=0.001, \mathrm{r}=0.42$; fig. 2$)$; the RDW level $(\mathrm{p}=0.001, \mathrm{r}=$ $0.43)$ and LVESV $(p=0.005, r=0.37)$ were positively correlated with OSI.

Oxidative Stress Index in Patients with Heart Failure

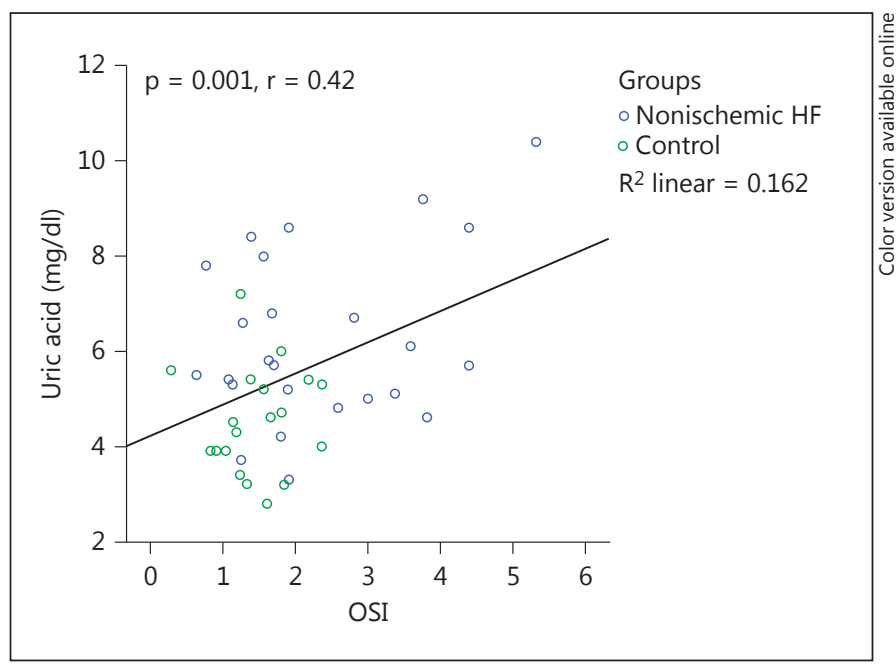

Fig. 2. Relationship between serum uric acid concentrations and OSI values in HF patients. In correlation analysis, we detected a nonlinear, moderate, positive relationship between the uric acid level and the OSI value in the HF and the control group ( $\mathrm{p}=0.001$, $\mathrm{r}=0.42$ ).

\section{Discussion}

In the present study, OSI levels, a marker of oxidative status, were significantly higher in the patients with nonischemic HF compared to the control subjects; uric acid and the TOS level were also higher in nonischemic HF patients compared to the control group. More importantly, OSI was positively correlated with RDW, LVESV, uric acid and the TOS level and negatively correlated with the TAC level and EF.

Oxidative stress results from an imbalance between ROS generation and antioxidant defensive mechanisms. ROS play a key role in the pathogenesis of a variety of cardiovascular diseases; the generation of increased levels of ROS has been shown to contribute directly to the progression of atherosclerosis, hypertension, reperfusion injury due to acute myocardial infarction and $\operatorname{HF}[18,19]$. A number of experimental and clinical studies have demonstrated an increased generation of ROS in HF patients [4-7]; hence, the activity of antioxidants may be reduced [20]. The importance of oxidative stress in HF patients may be associated with the process underlying LV hypertrophy, adverse LV remodeling and HF [21-23]. The most widely recognized effects of increased oxidative stress in the heart that cause cellular dysfunction, protein and lipid peroxidation, and DNA damage, leading to irreversible cell damage and death, have been implicated in a wide range of pathological cardiovascular conditions [3, 
24]. The role of oxidative stress is increasingly emerging with respect to a pathophysiological mechanism of cardiac remodeling responsible for the development and progression of HF $[3,24]$. Plasma lipid peroxidation, an indicator of oxidative stress, is increased in patients with dilated cardiomyopathy and positively correlates with the severity of symptoms $[25,26]$. Also, similar to our study, there is an inverse correlation between lipid peroxidation parameters and cardiac performance (EF, exercise capacity) [25]. These results may be associated with the effect of increased oxidative stress on LV remodeling and disease progression.

As in our study, Demirbag et al. [15] reported that OSI and uric acid levels increased in patients with idiopathic dilated cardiomyopathy. However, the TAC levels of plasma were significantly lower in the control subjects. Previous studies by Hill and Singal [6] demonstrated that HF subsequent to myocardial infarction was associated with an antioxidant capacity deficit as well as with increased oxidative stress. However, unlike these studies, we excluded HF due to ischemic etiology. Therefore, in our study, the TAC level was comparable in both groups but the TOS levels were significantly higher in the HF group. In addition, the uric acid level was moderately positively correlated with OSI (fig. 2). Similarly to our study, Demirbag et al. [15] found a negative correlation between EF and OSI. In an animal experiment, it was also reported that there was a significant negative correlation between the plasma lipid peroxidation product, malondialdehyde and LVEF $(r=0.35)$ [5]. Diraman et al. [27] found that antioxidant enzyme levels for patients with an EF $<25 \%$ were significantly lower than for patients with an $\mathrm{EF} \geq 25 \%$. A previous study has shown that in children with idiopathic dilated cardiomyopathy undergoing standard treatment, abnormal antioxidant enzyme activity was found [28]. Sezgin et al. [29] have found similar results in patients with less severe HF when an EF limit of $35 \%$ was used. In addition, Erdogan et al. [30] showed that a 3-month treatment with allopurinol, an antioxidant agent, was significantly associated with reduced uric acid levels and improvement in coronary flow reserve and LV functions in patients with idiopathic dilated cardiomyopathy and hyperuricemia. Based on the aforementioned data, we suggest that antioxidant treatment could be used widely in HF patients.

The limitations of this study include the small number of patients with nonischemic HF. In addition, the analysis was based on a simple baseline determination at a single time point, which might not reflect patient status over long periods.

\section{Conclusion}

The present study showed that OSI levels were significantly increased in patients with nonischemic HF compared to control participants. The change in TOS, OSI and uric acid levels in the study groups might indicate increased oxidative status in patients with HF. This may be associated with increased cardiovascular risk. Our findings also suggest that antioxidant treatment might be helpful for these patients. However, further prospective studies are needed to establish the pathophysiological and clinical significance of increased oxidative status in patients with HF.

\section{Disclosure Statement}

The authors have no conflicts of interest to declare.

\section{References}

$\checkmark 1$ McMurray JJ, Adamopoulos S, Anker SD, et al: ESC guidelines for the diagnosis and treatment of acute and chronic heart failure 2012: the Task Force for the Diagnosis and Treatment of Acute and Chronic Heart Failure 2012 of the European Society of Cardiology. Developed in collaboration with the Heart Failure Association (HFA) of the ESC. Eur J Heart Fail 2012;14:803-869.

2 Francis GS, Benedict C, Johnstone DE, et al: Comparison of neuroendocrine activation in patients with left ventricular dysfunction with and without congestive heart failure: a sub- study of the Studies of Left Ventricular Dysfunction (SOLVD). Circulation 1990;82: 1724-1729.

3 Seddon M, Looi YH, Shah AM: Oxidative stress and redox signalling in cardiac hypertrophy and heart failure. Heart 2007;93:903-907.

4 Sies H: Oxidative stress: oxidants and antioxidants. Exp Physiol 1997;82:291-295.

5 Belch JJF, Bridges AB, Scott N, et al: Oxygen free radicals and congestive heart failure. $\mathrm{Br}$ Heart J 1991;65:245-248.

6 Hill MF, Singal PK: Antioxidant and oxidative stress changes during heart failure subse- quent to myocardial infarction in rats. Am J Pathol 1996;148:291-300.

7 Hill MF, Singal PK: Right and left myocardial antioxidant responses during heart failure subsequent to myocardial infarction. Circulation 1997;96:2414-2420.

8 Mallat Z, Philip I, Lebret M, et al: Elevated levels of 8-iso-prostaglandin $\mathrm{F}_{2 \alpha}$ in pericardial fluid of patients with heart failure: a potential role for in vivo oxidant stress in ventricular dilatation and progression to heart failure. Circulation 1998;97:15361539. 
-9 Erel O: A new automated colorimetric method for measuring total oxidant status. Clin Biochem 2005;38:1103-1111.

10 Erel O: A novel automated method to measure total antioxidant response against potent free radical reactions. Clin Biochem 2004;37: 112-119.

-11 Demirbag R, Gur M, Yilmaz R, et al: Influence of oxidative stress on the development of collateral circulation in total coronary occlusion. Int J Cardiol 2007;116:14-19.

12 McMurray J, McLay J, Chopra M, et al: Evidence for enhanced free radical activity in chronic congestive heart failure secondary to coronary artery disease. Am J Cardiol 1990; 65:1261-1262.

13 McMurray J, Chopra M, Abdullah I, et al: Evidence of oxidative stress in chronic heart failure in humans. Eur Heart J 1993;14:14931498.

14 Diaz-Velez CR, Garcia-Castineiras S, Mendoza-Ramos E, et al: Increased malondialdehyde in peripheral blood of patients with congestive heart failure. Am Heart J 1996;131:146152.

15 Demirbag R, Yilmaz R, Erel O, et al: The relationship between potency of oxidative stress and severity of dilated cardiomyopathy. Can J Cardiol 2005;21:851-855.

16 Harma MI, Harma M, Erel O: Measuring plasma oxidative stress biomarkers in sport medicine. Eur J Appl Physiol 2006;97:505508.
17 Schiller NB, Shah PM, Crawford M, et al: American Society Echocardiography Committee on Standards, Subcommittee on Quantitation of Two-Dimensional Echocardiograms. Recommendations for quantitation of the left ventricle by two-dimensional echocardiography. J Am Soc Echocardiogr 1989;2: 358-367.

18 Byrne JA, Grieve DJ, Cave AC, et al: Oxidative stress and heart failure. Arch Mal Coeur Vaiss 2003;96:214-221.

19 Ungvari Z, Gupte SA, Recchia FA, et al: Role of oxidative-nitrosative stress and downstream pathways in various forms of cardiomyopathy and heart failure. Curr Vasc Pharmacol 2005;3:221-229.

20 Murdoch CE, Zhang M, Cave AC, et al: $\mathrm{NAD}(\mathrm{P}) \mathrm{H}$ oxidase-dependent redox signaling in cardiac hypertrophy, remodeling and failure. Cardiovasc Res 2006;71:208-215.

21 Suh YA, Arnold RS, Lassègue B, et al: Cell transformation by the superoxide-generating oxidase Mox1. Nature 1999;401:459-461.

22 Madamanchi NR, Vendrov A, Runge MS: Oxidative stress and vascular disease. Arterioscler Thromb Vasc Biol 2005;25:29-38.

23 Sorescu D, Griendling KK: Reactive oxygen species, mitochondria, and $\mathrm{NAD}(\mathrm{P}) \mathrm{H}$ oxidases in the development and progression of heart failure. Congest Heart Fail 2002;8:132140.

24 Takimoto E, Kass DA: Role of oxidative stress in cardiac hypertrophy and remodeling. Hypertension 2007;49:241-248.
25 Polidori MC, Pratico D, Savino K, et al: Increased $\mathrm{F}_{2}$ isoprostane plasma levels in patients with congestive heart failure are correlated with antioxidant status and disease severity. J Card Fail 2004;10:334-338.

26 Nakamura K, Kusano KF, Matsubara H, et al: Relationship between oxidative stress and systolic dysfunction in patients with hypertrophic cardiomyopathy. J Card Fail 2005;11: 117-123.

27 Diraman E, Demircan G, Demircan S, et al: Effect of glucose-insulin-potassium infusion on oxidative stress in patients with dilated cardiomyopathy. Exp Clin Cardiol 2008; 13 : 79-84.

28 Bajcetic M, Kokic Nikolic A, Djukic M, et al: Effects of carvedilol on left ventricular function and oxidative stress in infants and children with idiopathic dilated cardiomyopathy: a 12-month, two-center, open-label study. Clin Ther 2008;30:702-714

29 Sezgin N, Sezgin AT, Karabulut A, et al: Comparison of the antioxidant enzyme levels with the degree of dysfunction in patients with myocardial dysfunction. Anadolu Kardiyol Derg 2004;4:130-134.

30 Erdogan D, Tayyar S, Uysal BA, et al: Effects of allopurinol on coronary microvascular and left ventricular function in patients with idiopathic dilated cardiomyopathy. Can J Cardiol 2012;28:721-727. 